\title{
Effect of Al substrate microstructure on layered double hydroxide morphology
}

\author{
M. Richetta ${ }^{1, *}$ (D), E. Ciotta ${ }^{1}$ (D), R. Montanari ${ }^{1}$ (D), R. Narducci ${ }^{1}$ (D), R. Pizzoferrato ${ }^{1}$ (D), and \\ A. Varone ${ }^{1}$ (i) \\ ${ }^{1}$ Department of Industrial Engineering, University of Rome "Tor Vergata", Via del Politecnico 1, 00133 Rome, Italy
}

Received: 27 March 2019

Accepted: 21 May 2019

Published online:

28 June 2019

(C) Springer Science+Business Media, LLC, part of Springer Nature 2019

\begin{abstract}
Layered double hydroxides (LDHs) are 2D ionic lamellar nanomaterials, which attract increasing interest for applications in different fields. This paper shows that their morphology is strongly affected by the microstructure of the substrate on which they grow. $\mathrm{Zn}-\mathrm{Al} \mathrm{LDHs}$ were grown in the same conditions on $\mathrm{Al}$ substrates with different microstructural features obtained from cold-rolled sheets by annealing at $265^{\circ} \mathrm{C}$ for increasing soaking time up to $1 \mathrm{~h}$. LDH morphology was then investigated through scanning electron microscopy observations. The homogeneous distribution of petals on the substrate surface mainly depends on grain size distribution. A bimodal grain size distribution in the substrate leads to the formation of petal clusters and a not complete covering of the surface. In the case of grains of large size the nucleation sites are the dislocations forming the walls of the cells, while owing to their low density, the dislocations inside the grains are not a relevant factor in determining the LDH morphology.
\end{abstract}

\section{Introduction}

Layered double hydroxides (LDHs) are 2D ionic lamellar materials [1, 2]. These materials are quite interesting for industrial and medical applications owing to the possibility to exchange water molecules and several complex organic molecules within the inter-lamellar space [3]. LDHs have been employed as energy harvesting and conversion [4], anticorrosion coatings [2, 5, 6], catalysis [7], water treatment and purification [7], super hydrophobic surfaces [1], biomedical applications such as drug delivery and biosensors $[8,9]$ and nanostructured-modified textiles [9].

There are many synthesis techniques, which can be grouped into two main classes: direct and indirect methods [10-21].

A widely used direct method is the in situ film growth [18-21] that requires only immersion of the substrate in the aqueous solution of the other metal salt and a base for $\mathrm{pH}$ control. In principle, it should allow the deposition of LDH films on any surface, since it is sufficient to cover it with a layer of the reacting metal.

Address correspondence to E-mail: richetta@uniroma2.it 
Literature data show that there is a large variety of structures which can be obtained under different preparation conditions, but a good control of composition and morphology of the deposited film is still a challenging task. The main problem is a deep understanding of the specific role played by different parameters on nucleation and growth of LDHs; an aspect of particular relevance is the microstructural characteristics of the substrate.

Richetta et al. [22] deposited ( $\mathrm{Zn}-\mathrm{Al}$ ) LDHs on $\mathrm{Al}$ foils, observed the typical petal-like morphology and evidenced through ultraviolet photoemission spectroscopy (UPS) and X-ray photo-electron spectroscopy (XPS) a correlation between the petal size and $\mathrm{Al}$ content: as the $\mathrm{Al}$ content increases, the size of petals is reduced; thus, $\mathrm{Al}$ was supposed to be connected to the number of nucleation sites.

Forticaux et al. [23] demonstrated that the growth of LDH nanostructures is due to a dislocation-driven mechanism. This explanation is supported by recent analyses of Richetta [24] on the petal growth kinetics. Postulating that $\mathrm{LDH}$ growth rate is driven by $\mathrm{Al}$ diffusion, the activation energy $Q=0.73 \mathrm{eV}$ was determined, namely a value lower than the Al selfdiffusion energy $Q_{\mathrm{sd}}=1.31 \mathrm{eV}$ [25] and between the pipe diffusion energy $\left(Q_{\mathrm{p}}=0.85 \mathrm{eV}\right.$ [26]) and the grain boundaries diffusion energy $\left(Q_{\mathrm{gb}}=0.55 \mathrm{eV}\right.$ [27]). Therefore, $Q=0.73 \mathrm{eV}$ is an apparent activation energy not depending on a single physical phenomenon but on the diffusion along both grain boundaries and dislocations. As a matter of fact, lattice defects present in $\mathrm{Al}$ substrate seem to control the LDH growth.

In order to prepare LDHs with well-defined nanostructures and potentially improved properties, the present work aims to: (1) assess whether substrate microstructure plays a significant role on LDHs characteristics, (2) if this is the case, correlate the microstructural features of the substrate with those of LDHs. Therefore, the same preparation conditions $(\mathrm{pH}$, temperature, etc.) were adopted for the experiments of LDH growth on $\mathrm{Al}$ substrates with different microstructural features obtained through heat treatments at increasing time of cold-rolled sheets, and LDH morphology was correlated with substrate characteristics.

\section{Material and experimental}

The substrate material used in the present experiments was Al 99.99\%. The samples were $0.5-\mathrm{mm}$ thick sheets obtained by cold rolling a plate with reduction ratio of $98 \%$.

Al was characterized through optical microscopy $(\mathrm{OM})$, transmission electron microscopy (TEM) and $x$-ray diffraction (XRD). From XRD measurements the average grain size after cold rolling resulted to be $0.3 \mu \mathrm{m}$. TEM observations show that dislocations tend to form cells (Fig. 1a) while few dislocations are observed inside the grains (Fig. 1b). In general after relevant plastic deformation, the microstructure on the scale of our TEM observations is not homogeneous; therefore, the micrographs are useful to describe qualitatively the characteristic microstructural features, while average values of defects densities have been determined through XRD as described in detail in paragraph "Correlations between substrate microstructural features and LDH morphology".

To assess whether substrate microstructure plays a significant role on LDHs characteristics, a sample was deformed in a specific area through a punch of sintered tungsten carbide. LDHs were grown on a single sample to rule out external factors which could alter the results in the case of experiments with different samples (deformed and not deformed). A possible contamination of the imprint due to punching process has been verified through XPS measurements made on the $\mathrm{Al}$ surface inside and outside the imprint. The examined sample was previously submitted to the same preparation used to clean the surface before LDHs deposition. The XPS experiments were performed by using a monochromatized spectrometer Escalab 250Xi (Thermo Fisher Scientific, UK) equipped with six-channeltron detection system for spectroscopic analysis. The diameter of the examined area was about $1 \mathrm{~mm}$. Spectroscopic data were processed by the Avantage v. 5 software.

To examine the specific effect of different substrate microstructures on LDH growth, the cold-rolled sheets were annealed in vacuum $\left(10^{-3}\right.$ Torr $)$ at $265^{\circ} \mathrm{C}$ for increasing time up to $3600 \mathrm{~s}(1 \mathrm{~h})$ with steps of $600 \mathrm{~s}$. The treatments lead to recrystallization and grain growth, and the microstructure evolution is dependent on the annealing time.

The Al samples for metallographic observations were prepared through mechanical and 
Figure 1 TEM micrographs showing the microstructure of the Al substrate after cold rolling.
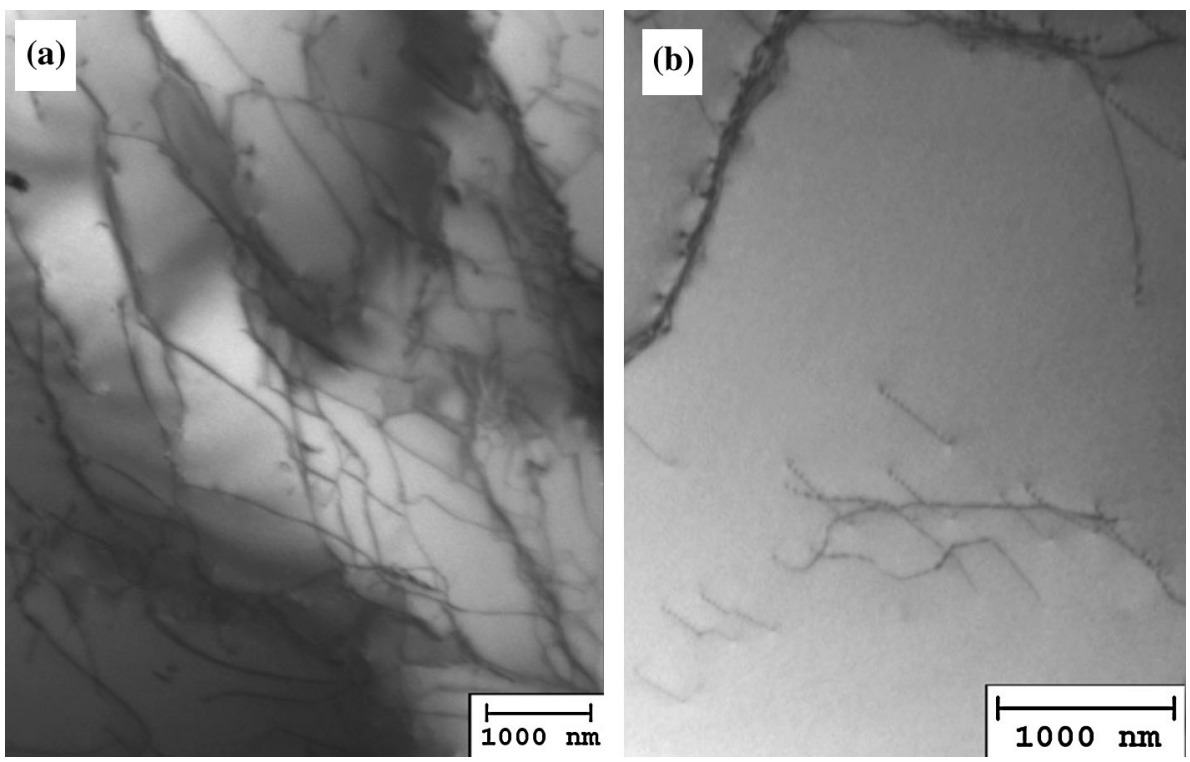

electrochemical polishing by using a $20 \%$ solution of perchloric acid in ethanol, cathode stainless steel, voltage $15 \mathrm{~V}$ and current density $=1 \mathrm{~A} / \mathrm{cm}^{2}$. Successive etching was made by means of the Barker's reagent $\left(5 \mathrm{ml} \mathrm{HBF}_{4}(48 \%)+200 \mathrm{ml} \mathrm{H}_{2} \mathrm{O}\right)$, cathode stainless steel, voltage $20 \mathrm{~V}$ and current density $0.2 \mathrm{~A} / \mathrm{cm}^{2}$. OM observations were carried out with polarized light.

XRD tests were performed using $\mathrm{Cu}-\mathrm{K} \alpha$ radiation $(\lambda=0.15408 \mathrm{~nm})$, and high precision peak profiles were collected in step-scanning mode with $2 \Theta$ steps of $0.005^{\circ}$ and $5 \mathrm{~s}$ of counting time per step. The Warren-Averbach method [28] was employed to determine the mean size of crystalline domains diffracting coherently and micro-strains due to lattice defects.

For the in situ growth of the LDH films, the $\mathrm{Al}$ substrates were first cleaned in distilled water and soap. They were then sonicated in $\mathrm{NaOH} 0.1 \mathrm{M}$ water solution for about $1 \mathrm{~min}$, rinsed with distilled water and sonicated for $10 \mathrm{~min}$ in ethanol. After rinsing in deionized water, the samples were immersed in a nutrient solution consisting of zinc nitrate $(5 \mathrm{mM})$ and urea $(15 \mathrm{mM})$ in a $500 \mathrm{ml}$ of distilled water $(\mathrm{pH}=7)$ and kept at $90{ }^{\circ} \mathrm{C}$ for $12 \mathrm{~h}$. Finally, the samples were extracted from the reactor and rinsed with ethanol and distilled water. The morphology of LDHs deposited on substrates with different microstructures has been investigated through scanning electron microscopy (SEM) observations.

\section{Results and discussion}

\section{Assessment of the effect of substrate microstructure on LDH morphology}

To assess whether the microstructure of the substrate plays a significant role on the LDHs characteristics, the following experiment has been carried out. As schematically shown in Fig. 2, a sheet of $\mathrm{Al}$ treated for $1 \mathrm{~h}$ at $450{ }^{\circ} \mathrm{C}$ has been submitted to heavy local deformation through deep indentation by means of a cylindrical punch $[29,30]$. In fact, a specific area with high density of lattice defects has been produced in a fully recrystallized $\mathrm{Al}$ matrix with low defect density. LDHs were then grown on this substrate to verify if differences of morphology resulted in the heavy deformed zone and matrix.

To assess possible contamination of the surface due to punching process, XPS measurements were made inside and outside the imprint. From the analysis of XPS spectra the relative amounts of $\mathrm{Al}$ (metallic and bond in $\left.\mathrm{Al}_{2} \mathrm{O}_{3}\right), \mathrm{C}$ and $\mathrm{O}$ were determined. The results reported in Table 1 do not evidence the presence of $\mathrm{W}$ due to the contact with the WC punch inside the imprint and relevant differences in the amounts of other elements between measurements performed inside and outside the imprint.

The Al substrate used in the experiment is displayed in the micrograph of Fig. 3a: the structure exhibits grains of large size $(\sim 70 \mu \mathrm{m})$ resulting from recrystallization and grain growth. Figures $3 b, c$ show that $\mathrm{LDH}$ morphological features are quite 
Figure 2 Schematic view of the Al substrate. An imprint was produced through a cylindrical punch of tungsten carbide.

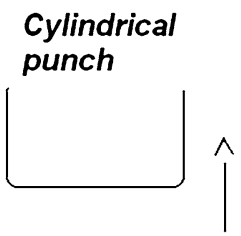

Fully recrystallized $A I$
Heavily deformed Al

Al substrate
Table 1 Relative amounts (at.\%) of metallic $\mathrm{Al}, \mathrm{Al}$ bond in $\mathrm{Al}_{2} \mathrm{O}_{3}, \mathrm{C}$ and $\mathrm{O}$ obtained by XPS spectra determined inside and outside the imprint

\begin{tabular}{lllll}
\hline & $\mathrm{Al}$ metallic (at.\%) & $\mathrm{Al}$ bond in $\mathrm{Al}_{2} \mathrm{O}_{3}$ (at.\%) & $\mathrm{C}$ (at.\%) & $\mathrm{O}$ (at.\%) \\
\hline Inside the imprint & 7.4 & 18.6 & 27.2 & 46.8 \\
Outside the imprint & 7.8 & 17.9 & 28.1 & 46.2 \\
\hline
\end{tabular}

different depending on the substrate microstructural state. In the zone with high deformation inside the imprint, petals exhibit a substantial homogeneous distribution even if some small petal clusters are observed (see Fig. 3b). Outside the imprint, petals grow much more densely and many petal clusters of large size are present (Fig. 3c). Although the results of this experiment are merely qualitative, they clearly demonstrate that the microstructure of substrate strongly affects the morphology of LDHs grown on it. On this basis the specific correlations between substrate microstructural features and LDH morphology have been investigated.

\section{Correlations between substrate microstructural features and LDH morphology}

To better understand the role played by the microstructural characteristics of the substrate on the $\mathrm{LDH}$ growth, samples cut from the same $\mathrm{Al}$ sheet and treated at $265^{\circ} \mathrm{C}$ for different times (up to $1 \mathrm{~h}$ ) have been used as substrates. In the cold-rolled sample (without any heat treatment), the grains are too small $(\sim 0.3 \mu \mathrm{m})$ to be investigated through $\mathrm{OM}$; thus, their size was determined by XRD. Owing to its high purity, after the first step of annealing at $265{ }^{\circ} \mathrm{C}$ (600 s) Al is fully recrystallized and grain growth has already started. Figure 4 shows a bimodal grain size distribution with grains of larger $(\sim 400 \mu \mathrm{m})$ and smaller $(\sim 15 \mu \mathrm{m})$ sizes; the last ones are assembled in clusters formed by tens of grains. Furthermore, the grains of smaller size are not homogeneously distributed on the surface as evident from the comparison of Fig. 4a, b which shows two different areas of the same sample.

Annealing for longer time leads to grains of progressively larger mean size; however, the bimodal size distribution is preserved even if the material tends to become more homogeneous and few clusters of small grains are observed after $1800 \mathrm{~s}$. For each heat treatment the mean grain size $D^{*}$ has been measured through image analysis carried out on 20 micrographs at the same magnification as those in Figs. 4 and 5.

XRD spectra were recorded on samples with LDH grown on different $\mathrm{Al}$ substrates, and in all the cases the diffraction patterns clearly display the reflections of both $\mathrm{Al}$ and $\mathrm{LDH}$; an example is given in Fig. 6 .

In Fig. 7 the mean grain size $D^{*}$ is plotted versus the annealing time at $265^{\circ} \mathrm{C}$ : it progressively increases and exhibits a significant slope change at $1800 \mathrm{~s}$. In correspondence of such change, all the XRD peak profiles show a broadening maximum; for example, the full width half maximum $\left(\beta_{220}\right)$ of the $\{220\}$ reflection is displayed. Since line broadening depends on both the size of coherently diffracting domains and micro-strains due to lattice defects, the $\beta$ maximum indicates that at least one of the two contributions abruptly increases. Gondi et al. [31, 32] demonstrated that grain growth of metals is not a continuous process, but proceeds by successive steps. These investigators performed internal friction measurements during isothermal grain growth of $\mathrm{Al}$ and other metals and detected some damping $\left(Q^{-1}\right)$ maxima spaced in the time scale. In correspondence 

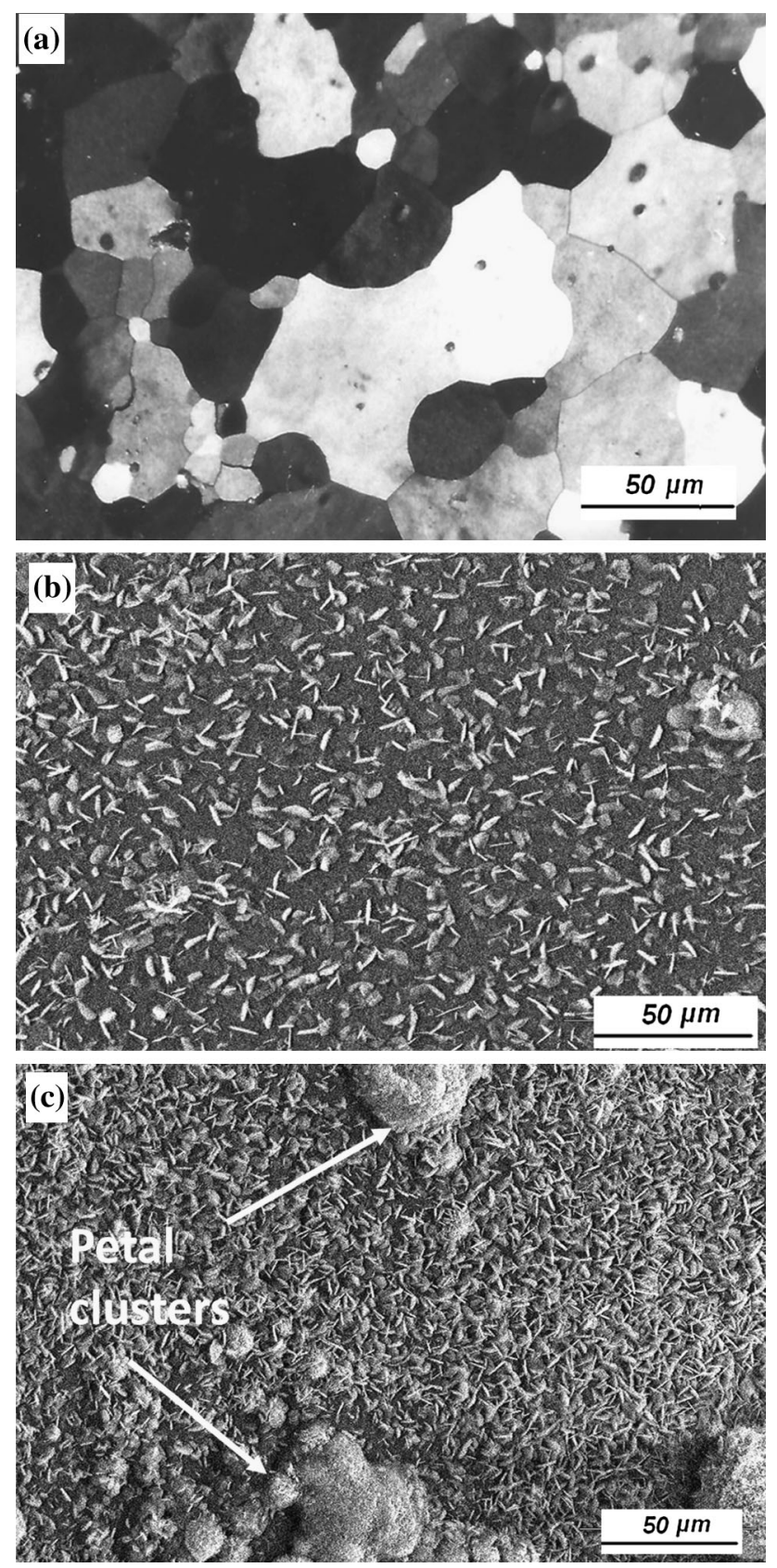

Figure 3 Grain structure of the $\mathrm{Al}$ substrate used for the experiment. LDH morphology in the zone with plastic deformation inside the imprint (b), and in original material outside the imprint (c).

of each maximum, they observed remarkable variations of the grain structure with the disappearing of grains of lower size. Each step corresponds to the formation of non-equilibrium grain boundaries which then collapse emitting free dislocations. More events (grain boundary collapse) occur in each step contributing to change the structure and giving rise to the damping maxima. The temporary increase in dislocations inside the grains, due to grain boundary collapse, causes the broadening of XRD peak profiles. This is in agreement with the present results: slope change in grain size curve and $\beta$ maximum are consistent with the occurrence of a grain growth step.

Owing to its high stacking fault energy $\left(\sim 160 \mathrm{~mJ} \mathrm{~m}^{-2}\right.$ ), cold-rolled $\mathrm{Al}$ exhibits a structure formed by dislocation cells whose size decreases as deformation rate increases; during recrystallization and grain growth the cellular structure is maintained even if the cell size increases [33]. Therefore, to assess possible correlations between microstructural features and LDH morphology, it is important to know not only the average grain size and the grain size distribution but also the density of dislocations in the cell walls and inside the cells because dislocations are preferred nucleation sites for petals [23].

To get values of statistical relevance, the density of dislocations inside the cells and in the cell walls has been determined from the analyses of precision XRD peak profiles (see Paragraph 2). The trend of mean square strains $\left\langle\varepsilon^{2}\right\rangle$ versus the atomic distances $L$ has been calculated through the Warren-Averbach method. The $\left\langle\varepsilon^{2}\right\rangle$ versus $L$ curves have been then fitted using the relationships determined by Wilkens $[34,35]$ for some simple dislocation distributions, i.e. free dislocations inside the cells $(I)$ and dislocations grouped in tilt boundaries $(B)$. The total square strain $\left\langle\varepsilon^{2}\right\rangle_{T}$ is the sum of the contributions $\left\langle\varepsilon^{2}\right\rangle_{I}$ and $\left\langle\varepsilon^{2}\right\rangle_{B}$ :

$\left\langle\varepsilon^{2}\right\rangle_{T}=\left\langle\varepsilon^{2}\right\rangle_{I}+\left\langle\varepsilon^{2}\right\rangle_{B}$

In the case of dislocations inside the grains, the mean square strain $\left\langle\varepsilon^{2}\right\rangle_{I}$ can be written as:

$\left\langle\varepsilon^{2}\right\rangle_{I}=\frac{1}{4 \pi^{2} B_{0}(p)}\left(\log \frac{1}{p}+2-\frac{3}{2 \pi} p-\frac{1}{8} p^{2}\right)\left(\frac{b^{2}}{(R / 2)^{2}}\right)$

being $R$ the distance between dislocations inside the cells, $p=2 L / R$ and

$B_{0}(p)=1-\frac{2}{\pi} p+\frac{1}{12 \pi} p^{3}+\frac{1}{320 \pi} p^{5}$

In the case of dislocations forming tilt boundaries, $\left\langle\varepsilon^{2}\right\rangle_{B}$ is given by:

$\left\langle\varepsilon^{2}\right\rangle_{B}=\frac{17 b^{2}}{128 \pi} \frac{1}{D d}\left[\log \frac{d}{L}+c\right]$ 

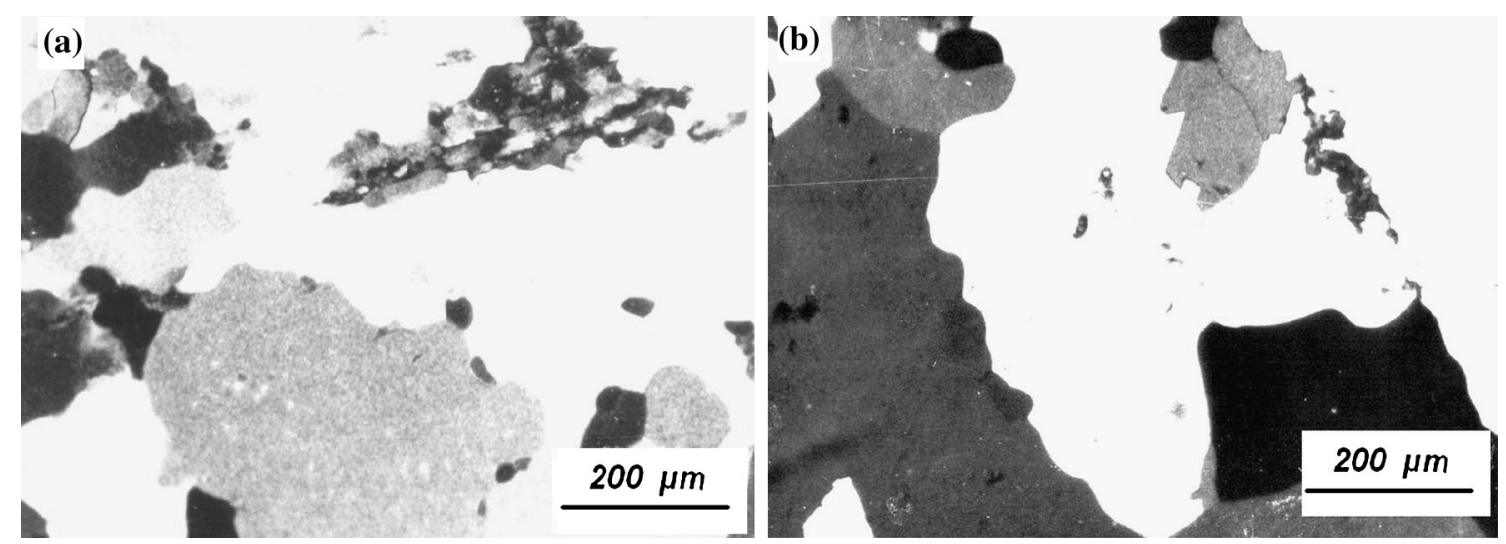

Figure 4 Two different zones of the same sample annealed at $265^{\circ} \mathrm{C}$ for $600 \mathrm{~s}$ with high (a) and low (b) number of small grains grouped in clusters.

where $D$ is the distance between the boundaries of the cell and $d$ is the distance between the dislocations in the boundary (Fig. 8a), $b=0.28567 \mathrm{~nm}$ is the modulus of Burgers vector and $c=1.376$ is a constant. An example is given in Fig. $8 \mathrm{~b}$ where the $\left\langle\varepsilon^{2}\right\rangle_{T}$ versus $L$ curve (open circles) of the cold-rolled sample obtained from Warren-Averbach analysis is fitted by $\left\langle\varepsilon^{2}\right\rangle_{T}$, sum of $\left\langle\varepsilon^{2}\right\rangle_{I}$ and $\left\langle\varepsilon^{2}\right\rangle_{B}$ contributions.

The values of $R, D$ and $d$ giving the best fit of $\left\langle\varepsilon^{2}\right\rangle_{T}$ versus $L$ curves are reported in Table 2 . From these values the density of dislocations inside the cells $\left(\rho_{I}\right)$, in tilt boundaries $\left(\rho_{B}\right)$ and the total density $\left(\rho_{T}\right)$ has been calculated as:

$\rho_{T}=\rho_{I}+\rho_{B}=\frac{1}{(2 R)^{2}}+\frac{1}{D d}$

XRD data in Table 2 show that the cell size $D$ increases with annealing time while the distance $d$ between dislocations in cell walls remains nearly constant. Putting together XRD and OM data, the microstructural evolution following annealing at increasing time can be described as follows:

1. after the first annealing step (600 s), the material is fully recrystallized and grain growth has already started;

2. grain growth is not a continuous process but proceeds by steps: in the time/temperature range examined here, a step is observed at $1800 \mathrm{~s}$;

3. grain size exhibits a bimodal distribution;

4. both grain size $D^{*}$ and cell size $D$ increase;

5. the number of cells in each grain increases as shown by the $D^{*} / D$ ratio (Fig. 9);
6. the mean distance $d$ between dislocations forming the cell walls does not substantially change;

7. in the cold-rolled condition, the dislocation density inside the cells is quite low with respect to that in cell walls and/or grain boundaries and further decreases after annealing.

Figure 10 shows SEM micrographs of LDHs grown on $\mathrm{Al}$ substrates in different conditions of annealing at $265{ }^{\circ} \mathrm{C}$, thus with different microstructures. $\mathrm{LDH}$ morphology exhibits some small variability from zone to zone on the surface of each single sample; however, the images are substantially representative of each sample and show great differences from sample to sample. In the cold-rolled sample LDHs are homogeneously distributed and completely cover the surface; petals of large size (10-12 $\mu \mathrm{m})$ are observed.

After the first step of annealing (600 s) the morphology and surface distribution of LDHs remarkably change: there are areas free from LDHs, the petals have a quite small size $(1-2 \mu \mathrm{m})$, and several petal clusters are observed. As annealing time increases, the morphology tends to become more homogeneous; in particular, after $1800 \mathrm{~s}$ a decreasing number of clusters are observed. The LDH morphology after $3000 \mathrm{~s}$ does not exhibit clusters at all.

Forticaux et al. [30] showed that the mechanism of LDH petal nucleation is strictly connected to dislocations and a dislocation-driven mechanism is generally responsible for the growth of $\mathrm{LDH}$ nanostructures. According to these investigators, complex structures such as petal clusters arise at a second stage from uncontrolled overgrowth from discrete dislocation-driven nanoplates and/or partial detachment of spiral layers. On this basis, both free 


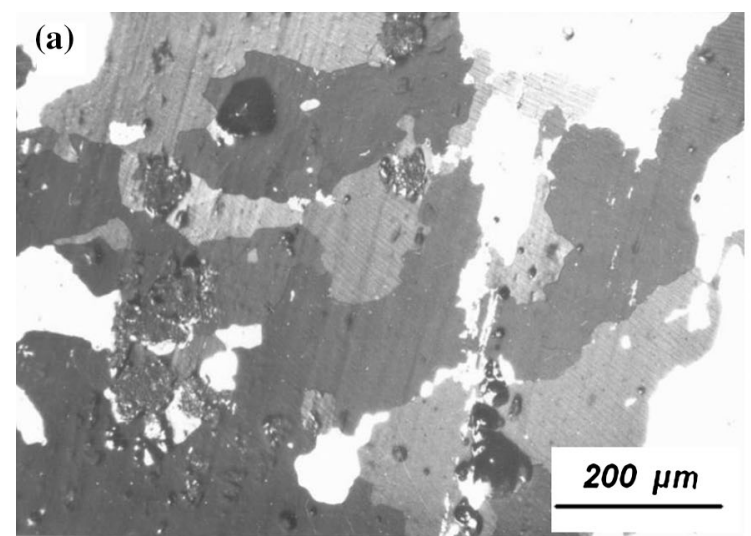

$1200 s$

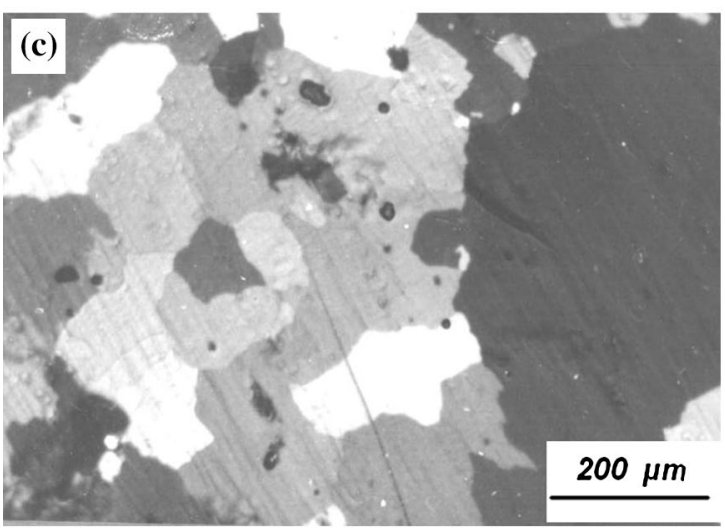

$2400 \mathrm{~s}$

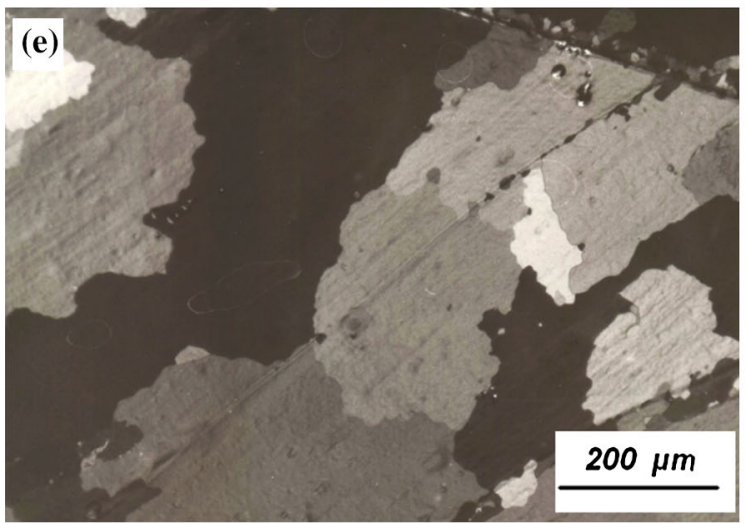

$3600 s$

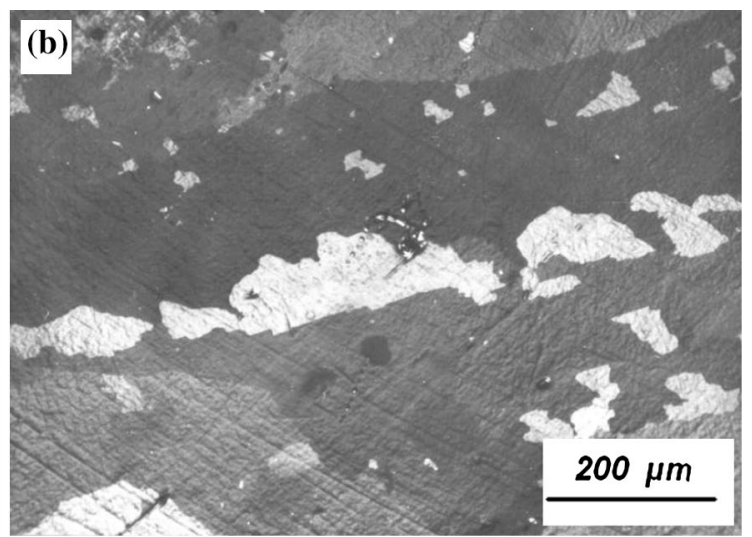

$1800 \mathrm{~s}$

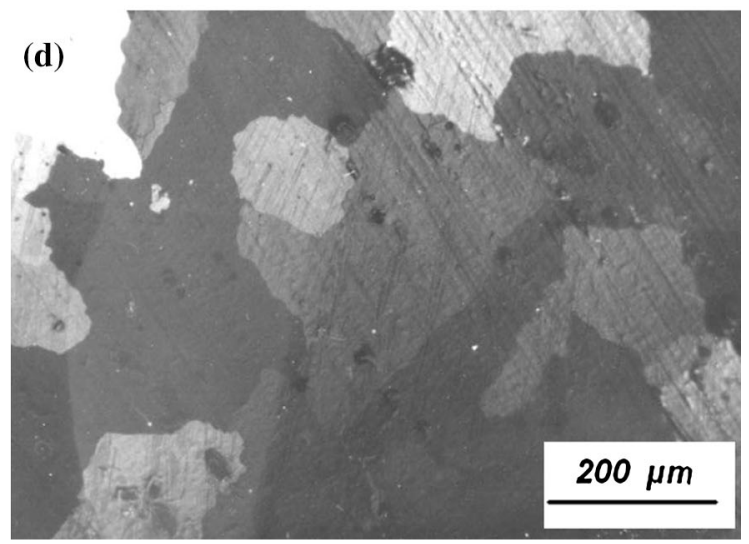

$3000 \mathrm{~s}$

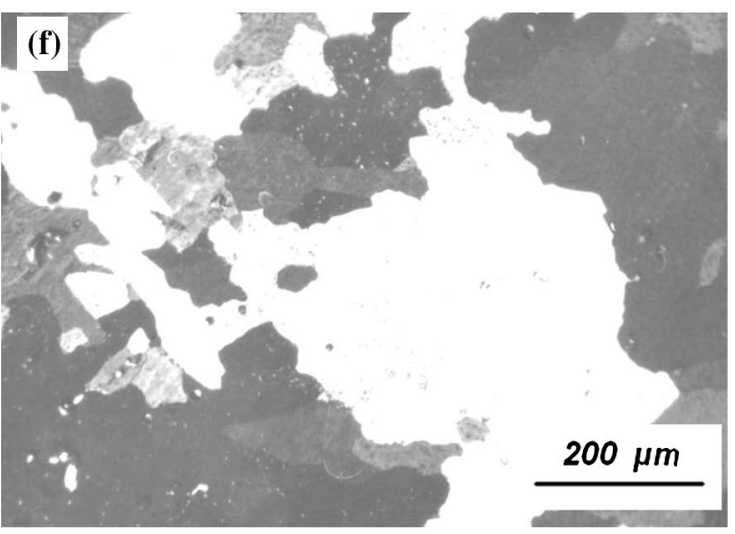

$3600 s$

Figure $5 \mathrm{OM}$ micrographs of the $\mathrm{Al}$ substrate after increasing time of annealing at $265{ }^{\circ} \mathrm{C}: 1200 \mathrm{~s}(\mathbf{a}), 1800 \mathrm{~s}(\mathbf{b}), 2400 \mathrm{~s}(\mathbf{c}), 3000 \mathrm{~s}(\mathbf{d})$, $3600 \mathrm{~s}(\mathbf{e}-\mathbf{f}))$.

dislocations inside the cells and dislocation networks forming grain boundaries and cell boundaries must be considered as preferred LDH nucleation sites.

$\mathrm{Al}$ is a high stacking fault metal, and its microstructure after plastic deformation can be described like a complex mosaic where each tessera (the grain) is formed by many domains (the cells). Of course, the dislocation density in grain boundaries is higher than that in cell boundaries because of the higher crystallographic misfit between grains than between cells. Generally, the density of free dislocations inside the cells is very low, but a temporary increase is observed when grain boundaries collapse during grain growth. 


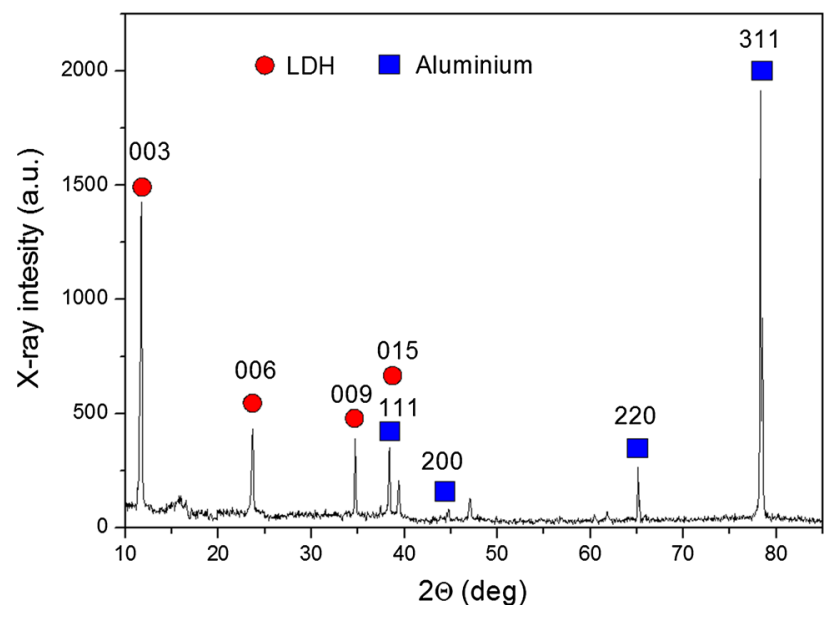

Figure 6 XRD pattern recorded from a sample where LDH was grown on a substrate cold-rolled without annealing.

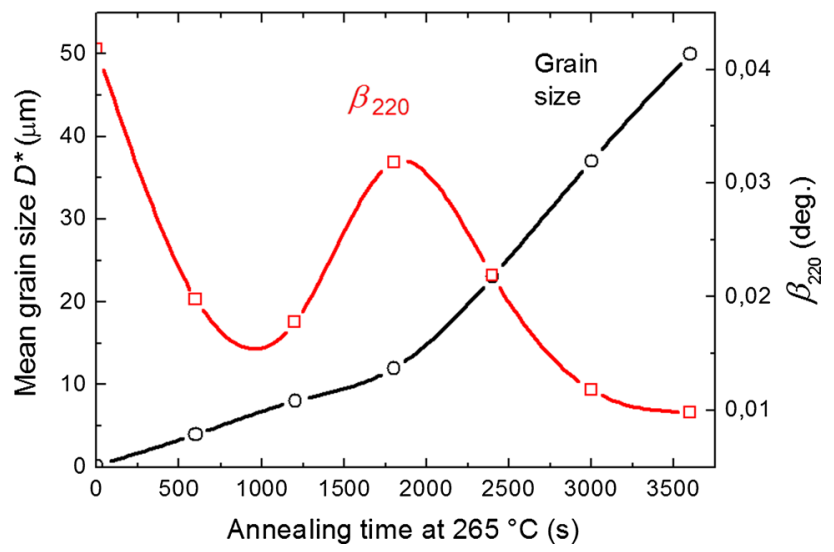

Figure 7 Mean grain size of $\mathrm{Al}$ substrate and full width half maximum of the $\{220\}$ XRD peak after different annealing times at $265{ }^{\circ} \mathrm{C}$.

The chemical reactions leading to nucleation and growth of LDH petals occur on the metal surface; therefore, the distribution of nucleation preferred sites, represented by dislocations inside the cells and dislocations organized in grain and cell boundaries, is of fundamental importance for LDH morphology. The dislocation distribution is statistically described by the following parameters: the mean grain size $D^{*}$ (Fig. 7) and grain size distribution (see Figs. 4, 5), the cell size $D$, the distance $d$ between the dislocations in cell boundaries and the distance $R$ between dislocations inside the cells (Table 2). The different morphologies observed by growing LDHs on substrates after different conditions of annealing can be discussed taking into account these parameters, and the results lead to the following considerations.
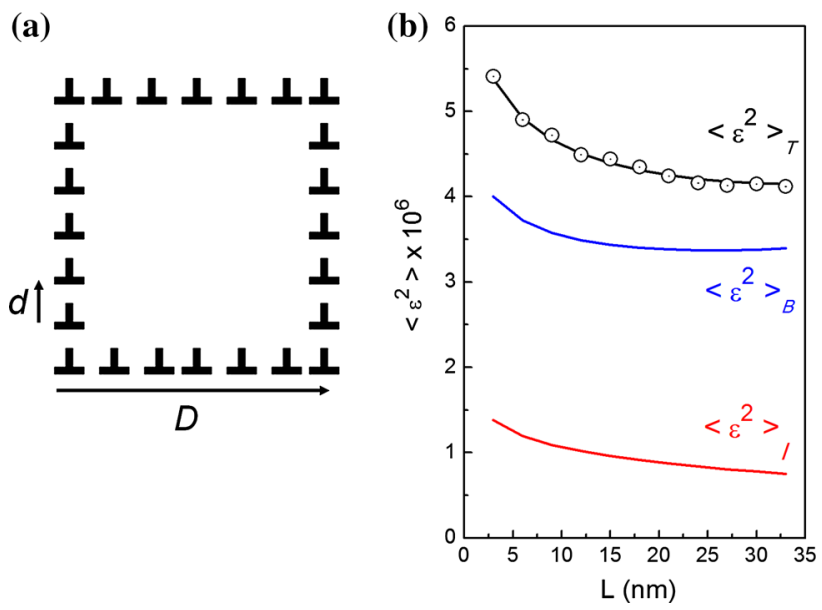

Figure 8 a Schematic view of the dislocation walls forming a cell. $D$ is the distance between the cell boundaries and $d$ the distance between the dislocations in the boundary. $\mathbf{b}$ Open circles indicate the values of $\left\langle\varepsilon^{2}\right\rangle_{T}$ versus the atomic distance $L$ determined from Warren-Averbach analysis. The interpolating curve represents the best fit of $\left\langle\varepsilon^{2}\right\rangle_{T}$ obtained as the sum of the two contributions, $\left\langle\varepsilon^{2}\right\rangle_{I}$ (dislocations inside the cells) and $\left\langle\varepsilon^{2}\right\rangle_{B}$ (dislocations in tilt boundaries).

1. In the conditions of the present experiments the growth rate is dominant with respect to the nucleation one since many hexagonal petals reach a size much larger than that of grains. This is evident in all the micrographs in Figs. 4 and 5; for example, the cold-rolled sample has a mean grain size of $\sim 0.3 \mu \mathrm{m}$, but several hexagonal petals are about $10 \mu \mathrm{m}$. Therefore, after nucleation LDH crystals grow rapidly and tend to inhibit the nucleation of other crystals from neighbouring nucleation sites.

2. When more LDH crystals are nucleated at the same time in neighbouring sites (dislocations), the growing crystals impinge on each other and it is reasonable that they could give rise to reactions similar to those between the dislocations around which they form; therefore, groups of grains of small size involving a local high dislocation density can give rise to structures like that shown in Fig. 11a which is the initial stage for the formation of a dome-shaped petal cluster. Such clusters can then grow developing complex morphologies (e.g. see Fig. 11b).

3. From the comparison of micrographs in Fig. 10, the homogeneous distribution of petals on the substrate surface seems to be strongly dependent on grain size distribution. When the substrates 
Table 2 Parameters giving the best fit of $\left\langle\varepsilon^{2}\right\rangle$ versus $L$ data and corresponding dislocation densities of the $\mathrm{Al}$ substrate

\begin{tabular}{lllllll}
\hline Treatment & $R(\mathrm{~nm})$ & $D(\mathrm{~nm})$ & $d(\mathrm{~nm})$ & $\rho_{I}\left(\mathrm{~m}^{-2}\right)$ & $\rho_{B}\left(\mathrm{~m}^{-2}\right)$ & $\rho_{T}\left(\mathrm{~m}^{-2}\right)$ \\
\hline Cold-rolled & 150 & 230 & 25 & $1.1 \times 10^{13}$ & $1.74 \times 10^{14}$ & $1.85 \times 10^{14}$ \\
$600 \mathrm{~s} / 265{ }^{\circ} \mathrm{C}$ & 300 & 335 & 23 & $2.78 \times 10^{12}$ & $1.30 \times 10^{14}$ & $1.32 \times 10^{14}$ \\
$1200 \mathrm{~s} / 265{ }^{\circ} \mathrm{C}$ & 280 & 630 & 28 & $3.19 \times 10^{12}$ & $5.69 \times 10^{13}$ & $5.99 \times 10^{13}$ \\
$1800 \mathrm{~s} / 265{ }^{\circ} \mathrm{C}$ & 170 & 820 & 21 & $8.65 \times 10^{12}$ & $5.81 \times 10^{13}$ & $6.67 \times 10^{13}$ \\
$2400 \mathrm{~s} / 265^{\circ} \mathrm{C}$ & 290 & 1100 & 24 & $2.97 \times 10^{12}$ & $3.79 \times 10^{13}$ & $4.09 \times 10^{13}$ \\
$3000 \mathrm{~s} / 265^{\circ} \mathrm{C}$ & 400 & 1300 & 27 & $1.56 \times 10^{12}$ & $2.85 \times 10^{13}$ & $3.00 \times 10^{13}$ \\
$3600 \mathrm{~s} / 265^{\circ} \mathrm{C}$ & 780 & 1480 & 28 & $4.11 \times 10^{11}$ & $2.41 \times 10^{13}$ & $2.45 \times 10^{13}$ \\
\hline
\end{tabular}

$R$ is the distance between dislocations inside the cells, $D$ the distance between the cell boundaries, $d$ the distance between the dislocations in the boundary, $\rho_{I}$ the dislocation density inside the cells, $\rho_{B}$ the dislocation density in tilt boundaries and $\rho_{T}=\rho_{I}+\rho_{B}$ the total density

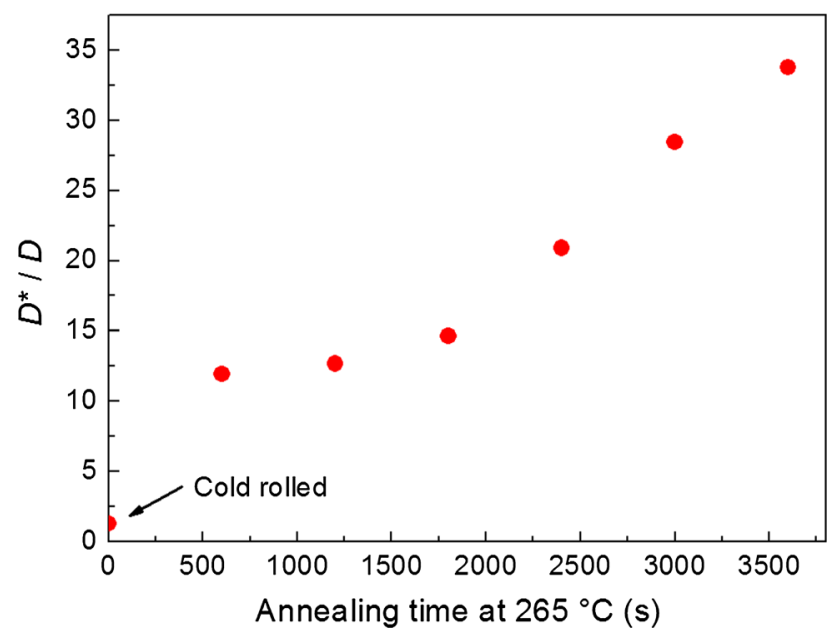

Figure $9 D^{*} / D$ ratio versus annealing time at $265^{\circ} \mathrm{C}$.

have a bimodal grain size distribution and the grains of smaller size are assembled in clusters, LDHs exhibit clusters of petals and the surface is not completely covered (e.g. see the samples annealed for $600 \mathrm{~s}$ at $265^{\circ} \mathrm{C}$ ). This can be ascribed to the not homogeneous distribution of nucleation sites on the surface: a lot of dislocations in grain boundaries are present in the zones with the smaller grains and a lower density in those of the larger ones. Therefore, petal clusters preferentially form in the zones with smaller grains because LDH crystals nucleating on neighbouring dislocations have not the possibility to freely grow and impingement soon occurs. In the zones with grains of larger size, LDH crystals form preferentially along the grain boundaries because there are few dislocations inside the grains so part of the surface remains uncovered.

4. In an advanced stage of grain growth (e.g. after $3000 \mathrm{~s}$ at $265^{\circ} \mathrm{C}$ ), the grains have a very large size and even if bimodal size distribution is still present, the smaller grains are no more clusterized. In this condition the dislocations forming the walls of the cells play an increasingly relevant role as nucleation sites. The result is a substantially homogeneous distribution of petals on the surface without petal clusters.

5. An homogeneous distribution of petals is observed also when the substrate is strongly deformed, for instance, in the cold-rolled condition (Fig. 10). In this case the grain size is quite small but the distribution is monomodal, namely there is an high density of dislocations but uniformly distributed on the surface.

6. Owing to their low density, the dislocations inside the grains are not a relevant factor in determining the LDH morphology.

From these considerations it is concluded that the final LDH morphology mainly depends on grain size distribution: the bimodal distribution typical of the initial stage of grain growth leads to petal clusters and partial surface covering, while a monomodal distribution, independently on the grain size, does not produce petal clusters.

On the basis of present results, one would also likely expect the underlying crystal orientation to have an effect since the number of dislocations intersecting the surface and their geometry will be affected by this. This aspect, which is not treated in detail in this work, deserves to be deepened in the future. 


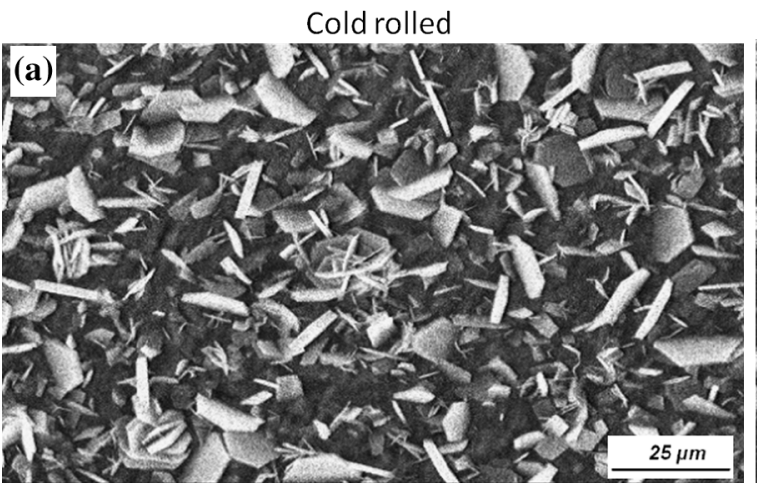

$1200 \mathrm{~s}$

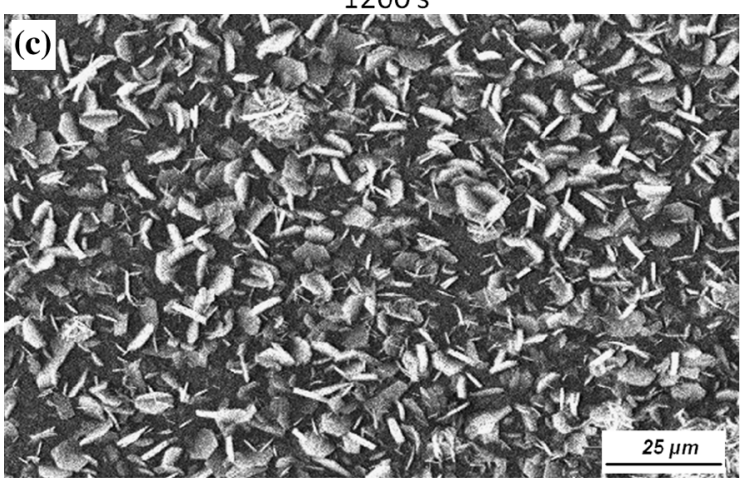

$2400 \mathrm{~s}$

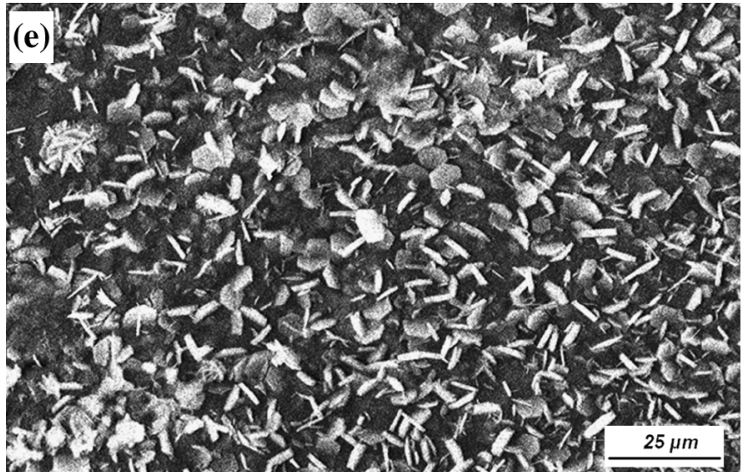

$3600 \mathrm{~s}$

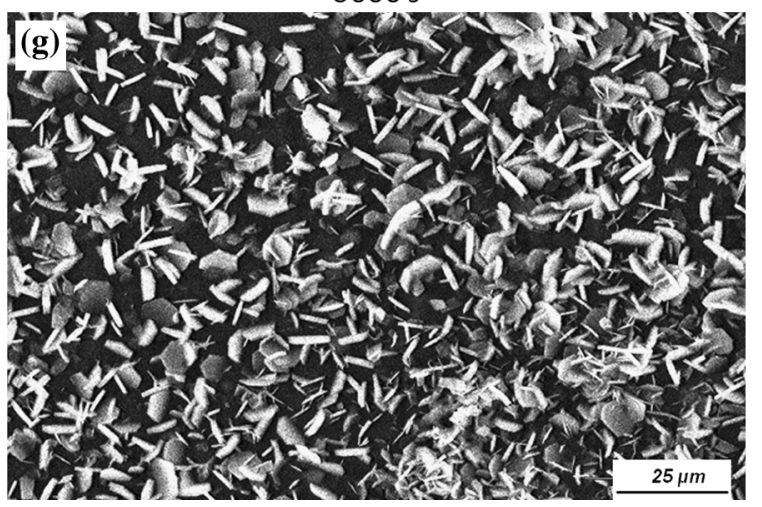

$600 \mathrm{~s}$

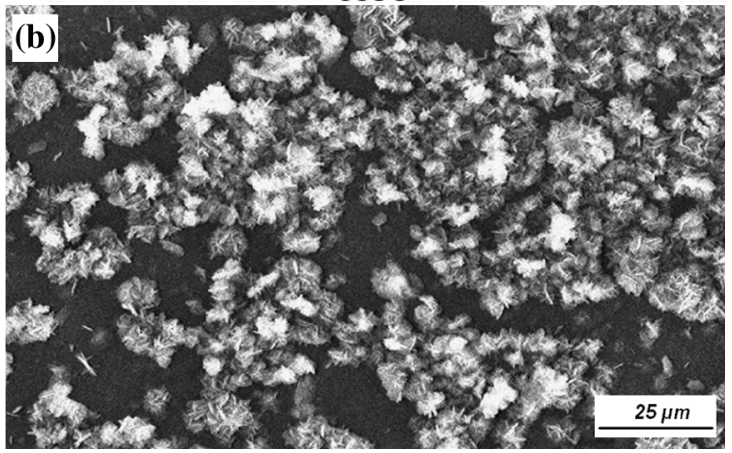

$1800 \mathrm{~s}$

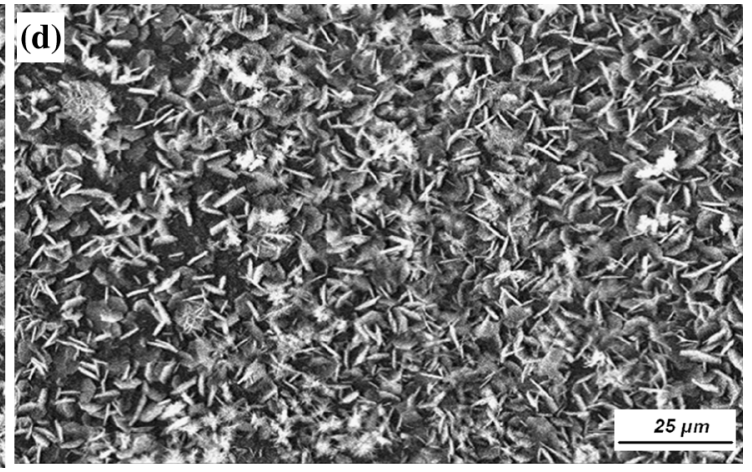

$3000 \mathrm{~s}$

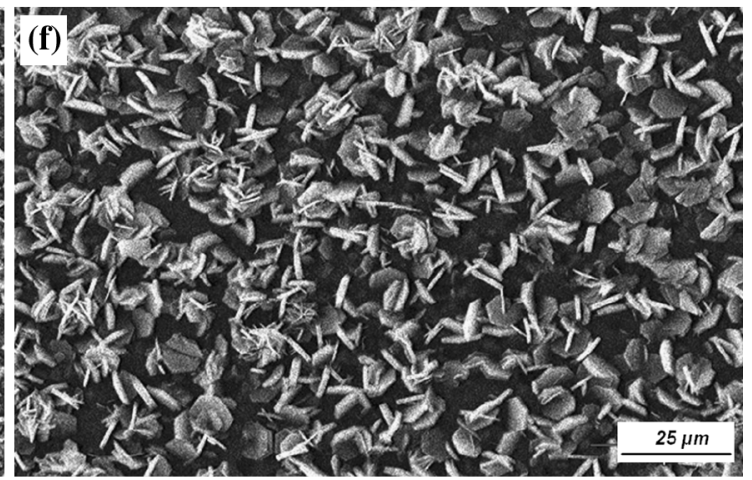

$$
\text { . }
$$



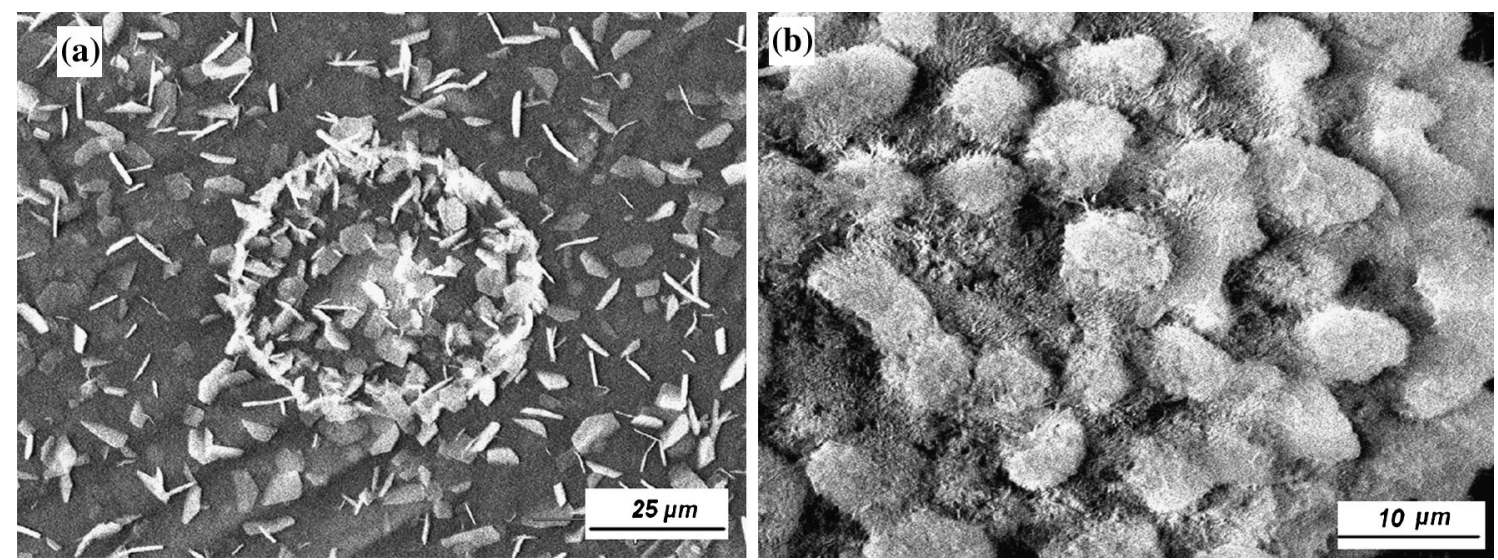

Figure 11 a Formation of a petal cluster in its initial stage. b Petal cluster of complex shape.

\section{Conclusions}

LDHs have been deposited on the surface of fully recrystallized samples, which were previously submitted to plastic deformation in a localized area through a cylindrical punch. LDH morphology, quite different in deformed and not deformed areas, demonstrates that the microstructure of the $\mathrm{Al}$ substrate plays a relevant role on the characteristics of LDHs grown on it.

To correlate the microstructural features of the substrate with the LDH morphology, they were grown on $\mathrm{Al}$ substrates with different microstructural features obtained by annealing cold-rolled sheets for increasing time at $265^{\circ} \mathrm{C}$.

Present results demonstrate that the distribution of LDH nucleation preferred sites, represented by dislocations inside the cells and dislocations organized in grain and cell boundaries, is the key parameter, which determines the LDH morphology.

The bimodal grain size distribution leads to petal clusters and a not complete surface covering. On the contrary, the monomodal distribution, independently on grain size, does not produce petal clusters and gives rise to a homogeneous surface covering.

Dislocations inside the grains do not seem to be a relevant factor in determining the LDH morphology.

\section{Compliance with ethical standards}

Conflict of interest The authors declare that they have no conflict of interest.

\section{References}

[1] Chen H, Zhang F, Fu S, Duan X (2006) In situ microstructure control of oriented layered double hydroxide monolayer films with curved hexagonal crystals as superhydrophobic materials. Adv Mater 18:3089-3093

[2] Shao M, Zhang R, Li Z, Wei M, Evans DG, Duan X (2015) Layered double hydroxides toward electrochemical energy storage and conversion: design, synthesis and applications. Chem Commun 51:15880-15893

[3] Pizzoferrato R, Ciotta E, Ferrari IV, Narducci R, Pasquini L, Varone A, Richetta M, Antonaroli S, Braglia M, Knauth P, Di Vona ML (2018) Layered double hydroxides containing an ionic liquid: ionic conductivity and use in composite anion exchange membranes. ChemElectroChem 5:2781-2788

[4] Long X, Wang Z, Xiao S, An Y, Yang S (2016) Transition metal based layered double hydroxides tailored for energy conversion and storage. Mater Today 19:213-226

[5] Guo L, Zhang F, Lu JC, Zeng RC, Li SQ, Song L, Zeng JM (2018) A comparison of corrosion inhibition of magnesium aluminum and zinc aluminum vanadate intercalated layered double hydroxides on magnesium alloys. Front Mater Sci 12:198-206

[6] Yao QS, Zhang F, Song L, Zeng RC, Cui LY, Li SQ, Wang ZL, Han EH (2018) Corrosion resistance of a ceria/polymethyltrimethoxylase modified $\mathrm{Mg}$-Al-layered double hydroxide on AZ31 magnesium alloy. J Alloys Compd 764:913-928

[7] De Roy A, Forano C, El Malki K, Besse JP (1992) Anionic clays: trends in pillaring chemistry. In: Occelli ML, Robson HE (eds) Expanded clays and other microporous solids. Springer, Boston, pp 108-169

[8] Kai Y, Wu G, Jin W (2016) Recent advances in the synthesis of layered double-hydroxide-based materials and their 
applications in hydrogen and oxygen evolution. Energy Technol 4:354-368

[9] Jung H, Ohashi H, Anilkumar GM, Zhang P, Yamaguchi T (2013) $\mathrm{Zn}^{2+}$ substitution effects in layered double hydroxide $\left(\mathrm{Mg}_{(1-\mathrm{x})} \mathrm{Zn}_{\mathrm{x}}\right)_{2} \mathrm{Al}$ : textural properties, water content and ionic conductivity. J Mater Chem A 1:13348-13356

[10] Zheng S, Lu J, Yan D, Qin Y, Li H, Evans DG, Duan X (2015) An inexpensive co-intercalated layered double hydroxide composite with electron donor-acceptor character for photoelectrochemical water splitting. Sci Rep 5:1-8

[11] Tadanaga K, Miyata A, Ando D, Yamaguchi N, Tatsumisago $\mathrm{M}$ (2012) Preparation of $\mathrm{Co}-\mathrm{Al}$ and $\mathrm{Ni}-\mathrm{Al}$ layered double hydroxide thin films by a sol-gel process with hot water treatment. J Sol Gel Sci Technol 62:111-116

[12] Chubar N, Gerda V, Megantari O, Mičušík M, Omastova M, Heister K, Man P, Fraissard J (2013) Applications versus properties of $\mathrm{Mg}-\mathrm{Al}$ layered double hydroxides provided by their syntheses methods: alkoxide and alkoxide-free sol-gel syntheses and hydrothermal precipitation. Chem Eng J 234:284-299

[13] Prinetto F, Ghiotti G, Graffin P, Tichit D (2000) Synthesis and characterization of sol-gel $\mathrm{Mg} / \mathrm{Al}$ and $\mathrm{Ni} / \mathrm{Al}$ layered double hydroxides and comparison with co-precipitated samples. Microporous Mesoporous Mater 39:229-247

[14] Li Y, Zhang L, Xiang X, Yan D, Li F (2014) Engineering of ZnCo-layered double hydroxide nanowalls toward high-efficiency electrochemical water oxidation. J Mater Chem A 2:13250-13258

[15] Liu X, Ma R, Bando Y, Sasaki T (2012) A general strategy to layered transition-metal hydroxide nanocones: tuning the composition for high electrochemical performance. Adv Mater 24:2148-2153

[16] Fang J, Li M, Li Q, Zhang W, Shou Q, Liu F, Zhang X, Cheng J (2012) Microwave-assisted synthesis of CoAl-layered double hydroxide/graphene oxide composite and its application in supercapacitors. Electrochim Acta 85:248-255

[17] Liu J, Huang X, Li Y, Sulieman KM, He X, Sun F (2006) Facile and large-scale production of $\mathrm{ZnO} / \mathrm{Zn}-\mathrm{Al}$ layered double hydroxide hierarchical heterostructures. J Phys Chem B 110:21865-21872

[18] Guo X, Xu S, Zhao L, Lu W, Zhang F, Evans DG, Duan X (2009) One-step hydrothermal crystallization of a layered double hydroxide/alumina bilayer film on aluminum and its corrosion resistance properties. Langmuir 25:9894-9897

[19] Guo X, Zhang F, Evans G, Duan X (2010) Layered double hydroxide films: synthesis, properties and applications. Chem Commun 46:5197-5210

[20] Scarpellini D, Leonardi C, Mattoccia A, Di Giamberardino L, Medaglia PG, Mantini G, Gatta F, Giovine E, Foglietti V, Falconi C, Orsini A, Pizzoferrato R (2015) Solution-grown
$\mathrm{Zn} / \mathrm{Al}$ layered double hydroxide nanoplatelets onto $\mathrm{Al}$ thin films: fine control of position and lateral thickness. J Nanomater. https://doi.org/10.1155/2015/809486

[21] Scarpellini D, Falconi C, Gaudio P, Mattoccia A, Medaglia PG, Orsini A, Pizzoferrato R, Richetta M (2014) Morphology of $\mathrm{Zn} / \mathrm{Al}$ layered double hydroxide nanosheets grown onto aluminum thin films. Microelectron Eng 126:129-133

[22] Richetta M, Digiamberardino L, Mattoccia A, Medaglia PG, Montanari R, Pizzoferrato R, Scarpellini D, Varone A, Kaciulis S, Mezzi A, Soltani P, Orsini A (2016) Surface spectroscopy and structural analysis of nanostructured multifunctional (Zn, Al) layered double hydroxides. Surf Interface Anal 48:514-518

[23] Forticaux A, Dang L, Liang H, Jin S (2015) Controlled synthesis of layered double hydroxide nanoplates driven by screw dislocations. Nano Lett 15:3403-3409

[24] Richetta M (2017) Characteristics, preparation routes and metallurgical applications of LDHs: an overview. J Mater Sci Eng 6:1-11

[25] Robinson SL, Sherby OD (1970) Activation energy for lattice self-diffusion in aluminium. Phys Status Solidi A 1:K119-K122. https://doi.org/10.1002/pssa.19700010333

[26] No ML, Esnouf C, San Juan J, Fantozzi G (1985) Dislocation motion in pure aluminium at $0.5 \mathrm{Tf}$ : analysis from internal friction measurements. Journal de Physique Colloques 46:C10-347-C10-350

[27] Levenson LL (1989) Grain boundary diffusion activation energy derived from surface roughness measurements of aluminium thin films. Appl Phys Lett 55:2617-2619

[28] Warren BE, Averbach BL (1950) The effect of cold-work distortion on X-ray patterns. J Appl Phys 21:595-599

[29] Gondi P, Montanari R, Sili A (1994) Small scale non-destructive stress-strain and creep tests feasible during irradiation. J Nucl Mater 212-215:1688-1692

[30] Gondi P, Donato A, Montanari R, Sili A (1996) A miniaturized test method for the mechanical characterization of structural materials for fusion reactors. $\mathrm{J}$ Nucl Mater 233-237:1557-1560

[31] Gondi P, Montanari R (1986) Dislocation emission in Al during recrystallization. Il Nuovo Cimento D 8:647-657

[32] Gondi P, Montanari R, Veniali F (1987) Relaxation and $\mathrm{X}$-ray diffraction line broadening phenomena during grain growth of metals. Journal de Physique Colloques 48:C8429-C8-434

[33] Humphrey FJ (1997) A unified theory of recovery, recrystallization and grain growth, based on the stability and growth of cellular microstructures-I. The basic model. Acta Mater 45:3949-4413 
[34] Wilkens M (1979) Diffraction line broadening of crystals containing small-angle boundaries. J Appl Crystallogr 12:119-125

[35] Wilkens M (1962) Zur Röntgenstreuung an Kristallen mit Versetzungen I. Zylinderförmiger Kristall axialer Schraubenversetzung. Phys Status Solidi 2:692-712
Publisher's Note Springer Nature remains neutral with regard to jurisdictional claims in published maps and institutional affiliations. 